\title{
ASSESSMENT OF THE MiCRoClimate IN THE WORK ENVIRONMENT
}

\section{ANDREJIOVA, M.; Kralikova, R.; WeSSEly, E. \& SOKOlOVA, H.}

Abstract: Microclimatic parameters are important factors in the physical environment which significantly affect the conditions of the working environment. These microclimatic parameters significantly affect the welfare of working people; define their subjective perception of well-being or discomfort. In case of extreme values, those can be perceived as harmful or adverse effects on human health. The paper is a contribution to assessment of thermo-humidity microclimate based on measurements with aim to give results about real conditions of the working environment.

Key words: working environment, microclimatic parameters, load environment, complex assessment of the load
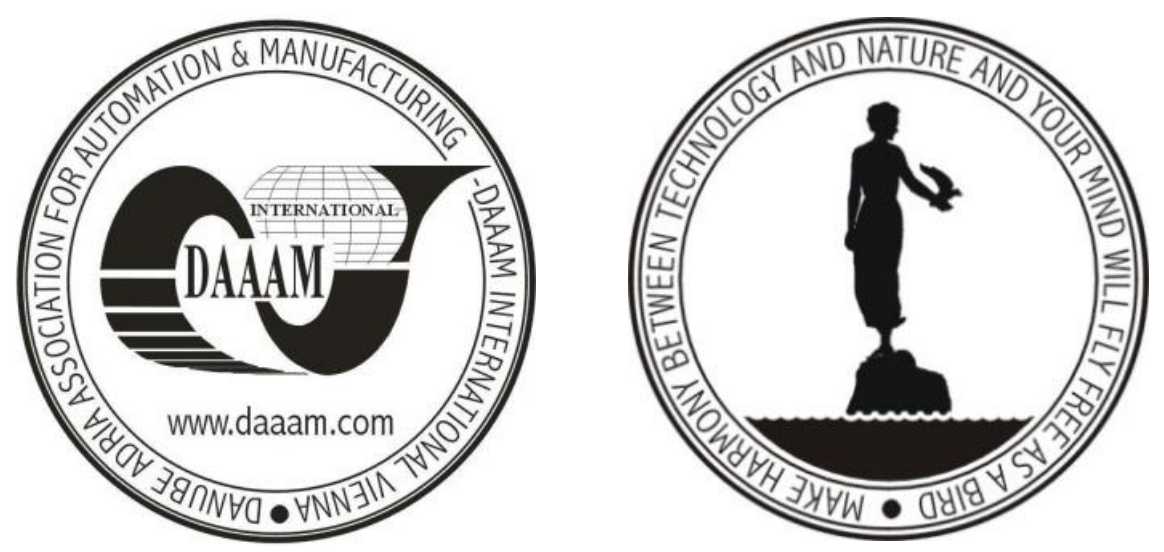

Authors' data: RNDr., PhD. Andrejiova, M[iriam]*; Doc. Ing., PhD. Kralikova, R[uzena]*, Doc. Ing. CSc. Wessely, E[mil]**; Sokolova, H[ana]*,*Technical University of Kosice, Letna 9, 040 01, Kosice, Slovakia, ** University of Security Management in Kosice, Kukucinova 17, 04001 Kosice, Slovakia, miriam.andrejiova@tuke.sk, ruzana.kralikova@tuke.sk, emil.wessely@vsbm.sk, hana.sokolova@tuke.sk

This Publication has to be referred as: Andrejiova, M[iriam]; Kralikova, R[uzena]; Wessely, E[mil] \& Sokolova, H[ana] (2012). Assessment of the Microclimate in the Work Environment, Chapter 42 in DAAAM International Scientific Book 2012, pp. 509-516, B. Katalinic (Ed.), Published by DAAAM International, ISBN 978-3901509-86-5, ISSN 1726-9687, Vienna, Austria

DOI: $10.2507 /$ daaam.scibook.2012.42 


\section{Introduction}

The work environment is an extensive summary of the factors that may affect its quality. In the area of the working environment it is necessary to draw attention not only to the most significant factors, but also to consider the impact of individual elements of a complex environment in which employees operate. Most common elements affecting the work environment are: noise, ventilation, temperature, humidity, light and stress.

Environmental well-being can be defined as state of the environment in which a person subjectively feels best and is capable of maximum performance, whether physical or mental. State of the environment in which human well-being is achieved, depends on several factors. Here belongs: air condition, wall temperature, temperature of surrounding objects, clothing, human subjective parameters, intensity of work and other effects (Hanker, 1978).

\section{Microclimatic parameters}

Microclimatic parameters (or conditions) of the work environment also known as thermal-moisture parameters are determined by temperature, relative humidity and airflow. These physical quantities define subjective well-being (comfort) or ill-being (discomfort). In extreme cases can be considered as pollutants with adverse effects on human health.

\subsection{Temperature}

Particular type of working class has got determined the optimal microclimate conditions, depending on body heat production affected by intensity of employee's activity. The total energy expenditure assigns the individual work activities to the working classes: 1a (sitting at work, administration), $1 \mathrm{~b}$ (standing at work), 1c (such us mechanics work, work in the steel industry), 2 (such as operating machines, work in the building industry), 3 and 4 (intensive and very intensive work).

\begin{tabular}{|c|c|c|c|c|}
\hline \multirow{2}{*}{$\begin{array}{c}\text { Working } \\
\text { class }\end{array}$} & \multicolumn{4}{|c|}{ Temperature $\left[{ }^{\circ} \mathbf{C}\right]$} \\
\cline { 2 - 5 } & Optimal temperature & Permissible temperature \\
\cline { 2 - 5 } 1a & Warm season & Cold season & Warm season & Cold season \\
\hline 1b & $21-25$ & $20-23$ & $20-28$ & $20-26$ \\
\hline $\mathbf{1 c}$ & $20-24$ & $18-21$ & $18-26$ & $17-24$ \\
\hline $\mathbf{2}$ & $18-22$ & $15-19$ & $16-25$ & $13-22$ \\
\hline $\mathbf{3}$ & $16-19$ & $12-17$ & $12-24$ & $10-20$ \\
\hline $\mathbf{4}$ & \multicolumn{4}{|c|}{ The value does not determine } \\
\hline
\end{tabular}

Tab.1. The optimal and permissible temperature for some working class

Range of optimal values of microclimatic conditions in the working environment is set for a warm period (average daily outdoor temperature $13^{\circ} \mathrm{C}$ and 
more) and winter season (decrease of the average daily temperature for two consecutive days below $13^{\circ} \mathrm{C}$ ). The optimal and permissible temperatures for warm and cold season of the year are in the Table 1 (Slovak Directive No. 544/2007).

In case of the workplace with long-term nature where it is impossible to provide optimal conditions, the employer is required to ensure compliance with permissible microclimatic conditions. Exceptions are in need of special workplaces where the burden of heat or cold is impossible to be removed due to various technological reasons.

\subsection{Humidity}

Humidity in the working environment is a specific factor. The specificity of factor is mainly in the fact that unlike the temperature, this can be subjectively very difficult to perceive and then evaluated. The human body can have an adverse effect on the decrease in humidity on the level of $20 \%$ mainly in winter (due to heating) and the humidity in excess of the $60 \%$ in other seasons. The scope of permissible values of relative humidity is in the Table 2 (Kubani, 1998).

\begin{tabular}{|c|c|l|}
\hline Temperature & Humidity & \multicolumn{1}{|c|}{ Working performance } \\
\hline \multirow{3}{*}{$\mathbf{2 1}^{\circ} \mathbf{C}$} & $40 \%$ & Very good \\
\cline { 2 - 3 } & $85 \%$ & Good at changing work and rest \\
\cline { 2 - 3 } & $91 \%$ & Reduced, there is a fatigue and depression \\
\hline \multirow{3}{*}{$\mathbf{2 6}^{\circ} \mathbf{C}$} & $30 \%$ & Very good \\
\cline { 2 - 3 } & $65 \%$ & Reduced, rapid fatigue \\
\cline { 2 - 3 } & $80 \%$ & Difficult, the need for frequent rest \\
\hline \multirow{4}{*}{$\mathbf{3 2}^{\circ} \mathbf{C}$} & $25 \%$ & Very good \\
\cline { 2 - 3 } & $50 \%$ & Strongly reduced performance \\
\cline { 2 - 3 } & $65 \%$ & Work is almost impossible \\
\cline { 2 - 3 } & $81 \%$ & Exhaustive, leads to an increase in body temperature \\
\cline { 2 - 3 } & $90 \%$ & Work threatens health \\
\cline { 2 - 3 } & $100 \%$ & Work is impossible \\
\hline
\end{tabular}

Tab. 2. Relationship of temperature, humidity and work performance

\subsection{Airflow}

In practice it is often not possible to keep the airflow and the intensity at a low level to ensure a comfortable working environment. Difficulties were encountered in most cases, particularly for space cooling. Increasing airflow increases the flow of cooling the body and decreases the amount of sweat produced (Slovak Directive No. 544/2007).

The velocity of airflow in the place is to create thermal comfort environment of considerable importance. People with sedentary work in confined spaces are more responsive to airflow than the movement in the nature. In case of temperature and as well as for airflow factor values exist. These should be respected in the work environment. Summary of values for each type of working class is shown in Table 3 (Franko, S. at al. , 2011). 
Andrejiova, M.; Kralikova, R.; Wessely, E. \& Sokolova, H.: Assessment of the Microcli...

\begin{tabular}{|c|c|c|c|c|}
\hline \multirow{2}{*}{$\begin{array}{c}\text { Working } \\
\text { class }\end{array}$} & \multicolumn{2}{|c|}{$\begin{array}{c}\text { Permissible velocity } \\
\text { of airflow [ms }\end{array}$} & \multicolumn{2}{c|}{ Permissible humidity [\%] } \\
\cline { 2 - 5 } & Warm season & Cold season $^{-1}$ & Warm season & Cold season \\
\hline 1a & $\leq 0,25$ & $\leq 0,20$ & $30-70$ & $30-70$ \\
\hline 1b & $\leq 0,30$ & $\leq 0,25$ & $30-70$ & $30-70$ \\
\hline 1c & $\leq 0,30$ & $\leq 0,30$ & $30-70$ & $30-70$ \\
\hline $\mathbf{2}$ & $0,1-0,3$ & $\leq 0,30$ & $30-70$ & $30-70$ \\
\hline $\mathbf{3}$ & \multicolumn{3}{|c|}{ The value does not determine } \\
\hline $\mathbf{4}$ & \multicolumn{3}{|c|}{} \\
\hline
\end{tabular}

Tab. 3. The value of permissible velocity of airflow and humidity

\section{Method}

The working environment is characterized by a set of negative factors at any time varying by intensity of effect on the human organism during work. Complex work load is the total of external conditions and requirements in the working system adversely affecting the health of humans.

To evaluate the work load is commonly used the value $q$ that represents how many times the actual load factor of a given work environment is more than the permissible load (Kapustova, 2004). Relationship applies:

$$
q=\frac{F^{r}}{F^{p}}
$$

where $F^{r}$ is real load and $F^{p}$ is permissible load factors.

By using methods of mathematical statistics mathematical model was developed. This allows to express a summary effect of negative environmental factors and to evaluate the complex load of the human body during work. In any work environment more load factors affect on people during the workday. The total load of these factors $F$ can be expressed as the result of all load factors:

$$
F=F_{1}+F_{2}+F_{3}+\cdots+F_{n}
$$

where $F_{j}, j=1,2, \ldots, n$ are load factors that affect the human body.

It is known that not all of the factors involved in the total load equal weights. For this reason, the load factor $F_{j}, j=1,2, \ldots, n$ has the weight of the load $\alpha_{j}$ with the condition:

$$
\alpha_{1}+\alpha_{2}+\alpha_{3}+\cdots+\alpha_{n}=1, \alpha_{j} \in(0 ; 1), j=1,2, \ldots, n,
$$

where $\alpha_{j}, j=1,2, \ldots, n$ are coefficients of severity impact factors of working environment (Kapustova, 2004). 
The principle and method of determining the coefficients $\alpha_{j}, j=1,2, \ldots, n$ is described at the Table 4 . The point value $b_{i j}$ is the impact of load factor $F_{j}$ on the health and some parts of the human body $T_{i}$ (Kapustova, 2004).

\begin{tabular}{|c|c|c|c|c|c|c|}
\hline \multirow{2}{*}{ Body parts } & \multicolumn{5}{|c|}{ Load factors } & \multirow{2}{*}{ Sum } \\
\cline { 2 - 7 }$T_{1}$ & $F_{1}$ & $F_{2}$ & $F_{3}$ & $\ldots$ & $F_{n}$ & $b_{1 n}$ \\
\hline$T_{2}$ & $b_{12}$ & $b_{13}$ & $\ldots$ & $\sum_{j=1}^{n} b_{1 j}$ \\
\hline$\ldots$ & $b_{21}$ & $b_{22}$ & $b_{23}$ & $\ldots$ & $b_{2 n}$ & $\sum_{j=1}^{n} b_{2 j}$ \\
\hline$T_{k}$ & $b_{k 1}$ & $b_{k 2}$ & $b_{k 3}$ & $\ldots$ & $b_{k n}$ & $\sum_{j=1}^{n} b_{k j}$ \\
\hline Sum & $\sum_{i=1}^{k} b_{i 1}$ & $\sum_{i=1}^{k} b_{i 2}$ & $\sum_{i=1}^{k} b_{i 3}$ & $\ldots$ & $\sum_{i=1}^{k} b_{i n}$ & $\sum_{i=1}^{k} \sum_{j=1}^{n} b_{i j}$ \\
\hline
\end{tabular}

Tab. 4. Principle of the method

The coefficient values $\alpha_{j}, j=1,2, \ldots, n$ are determined by a point method which is based on the allocation of points in the scale of 0 to 10 and its applications for each type of load $F_{j}$ of the individual health and well-being human body parts $T_{i}$ by work activity (Table 4). Relationship applies

$$
\alpha_{1}=\frac{\sum_{i=1}^{k} b_{i 1}}{\sum_{i=1}^{k} \sum_{j=1}^{n} b_{i j}}, \alpha_{2}=\frac{\sum_{i=1}^{k} b_{i 2}}{\sum_{i=1}^{k} \sum_{j=1}^{n} b_{i j}}, \ldots, \alpha_{n}=\frac{\sum_{i=1}^{k} b_{i n}}{\sum_{i=1}^{k} \sum_{j=1}^{n} b_{i j}} .
$$

These coefficients characterize the degree of load on the human body. The value close to 0 reflects the modest impact of load factor. The value close to 1 means a significant impact of factor.

For each working class are known values of the permissible load $F_{j}^{p}$; for the individual load factors $F_{j}$ and we can always determine real load $F_{j}^{r}$. Immediate complex working load is given by

$$
q_{C}=\alpha_{1} \frac{F_{1}^{r}}{F_{1}^{p}}+\alpha_{2} \frac{F_{2}^{r}}{F_{2}^{p}}+\cdots+\alpha_{n} \frac{F_{n}^{r}}{F_{n}^{p}}=\sum_{j=1}^{n} \alpha_{j} \frac{F_{j}^{r}}{F_{j}^{p}}
$$

where $\alpha_{j} \frac{F_{j}^{r}}{F_{j}^{p}}, j=1,2, \ldots, n$ defines the degree of real load human body with factor $F_{j}$ (Kapustova, 2004; Hnilica, 2011). 


\section{Complex assessment of the work load}

In assessing the impact of microclimatic parameters (temperature, humidity, airflow) for comfort of working environment, we chose one engineering company in Slovakia. Measurement of microclimatic parameters was held in the building of the production hall. The measurement points were chosen to represent the place of residence of employee performance during working hours.

Effect of load parameters were observed on sweating, breathing, psychological well-being at work, cervical and lumbar spine and the hearing organs. The average values of coefficients are obtained by a point method, which involved five employees (Table 5). The calculations show that $\alpha_{1}=0,4107, \alpha_{2}=0,2143$ and $\alpha_{3}=0,3750$.

\begin{tabular}{|l|c|c|c|c|}
\hline \multirow{2}{*}{ Impact on } & Temperature & Humidity & Airflow & \multirow{2}{*}{ Sum } \\
\cline { 2 - 4 } & Points & Points & Points & \\
\hline Sweating & 9 & 4 & 2 & $\mathbf{1 5}$ \\
\hline Breathing & 6 & 4 & 3 & $\mathbf{1 3}$ \\
\hline $\begin{array}{l}\text { Psychological well-being } \\
\text { at work }\end{array}$ & 7 & 3 & 3 & $\mathbf{1 3}$ \\
\hline Cervical and lumbar spine & 1 & 1 & 7 & $\mathbf{9}$ \\
\hline Hearing organs & 0 & 0 & 6 & $\mathbf{6}$ \\
\hline Sum & $\mathbf{2 3}$ & $\mathbf{1 2}$ & $\mathbf{2 1}$ & $\mathbf{5 6}$ \\
\hline
\end{tabular}

Tab.5. Results of the method

Based on results, the temperature has a clear effect on excessive sweating at work, which also affected the psychological well-being and shortness of breath conditions. The evaluation of the humidity does not work very negatively on the human body. Possible increased humidity is reflected by excessive sweating, difficulty in breathing and also distress at work. The third factor airflow significantly affects the hearing organs and lumbar and cervical spine.

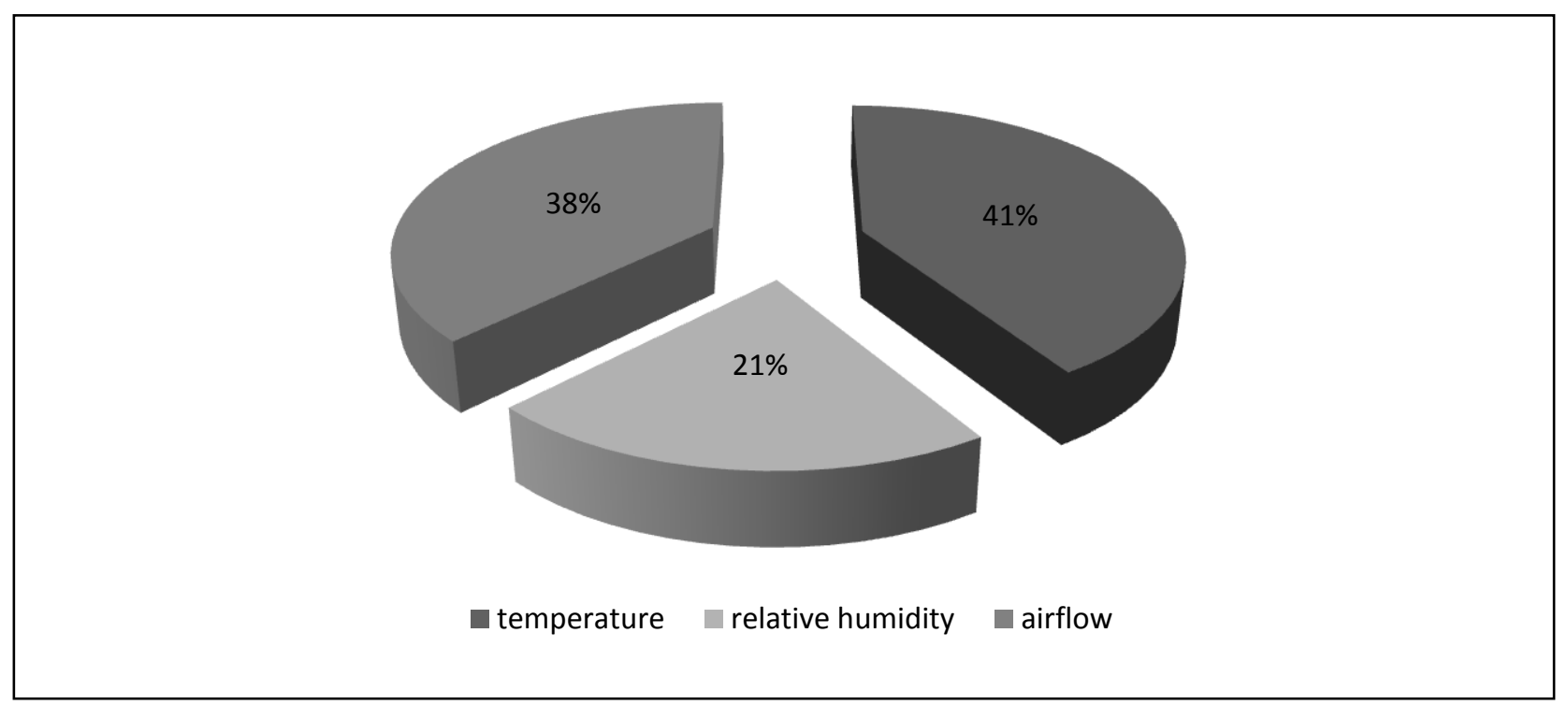

Fig. 1. The values of the coefficients 
To create comfort in the work environment, temperature and airflow are main factors. According to research results is the temperature to $41 \%$ of the discomfort and dissatisfaction in the work environment (Fig.1). Approximately the same impact on the overall discomfort is also factor airflow (nearly $38 \%$ ).

The complex working load of microclimatic conditions in the work environment was carried out during working hours from 8.00 to 13.00. The measured values of the real load factors $F_{j}^{r}$ together with the complex working load are in the following Table 6. Permissible load $F_{j}^{p}$ for the relevant working class is specified in the Slovak directive No. 544/2007. The benchmark is considered the value $q_{C}=1$.

\begin{tabular}{|c|c|c|c|c|}
\hline Measurement & Temperature & Humidity & Airflow & Complex load \\
\hline $8: 00$ & 21,8 & 55,3 & 0,11 & 0,883 \\
\hline $9: 00$ & 24,9 & 50,3 & 0,12 & 0,934 \\
\hline $10: 00$ & 25,7 & 48,2 & 0,11 & 0,911 \\
\hline $11: 00$ & 26,5 & 44,0 & 0,18 & 1,079 \\
\hline $12: 00$ & 27,0 & 45,6 & 0,22 & 1,195 \\
\hline $13: 00$ & 24,5 & 44,6 & 0,13 & 0,925 \\
\hline
\end{tabular}

Tab. 6. The measured values of load and complex working load

The results show that measuring with the value of a complex assessment of the load less than 1 can be considered satisfactory. If that was exceeded at least in one admissible value, the resulting value of a complex evaluation is larger than 1 (Fig. 2).

In this case, it is the zone with working discomfort and high-harmful effect on human body. Zone, in which the value is near to 1 , can be considered permissible with slightly detrimental effects.

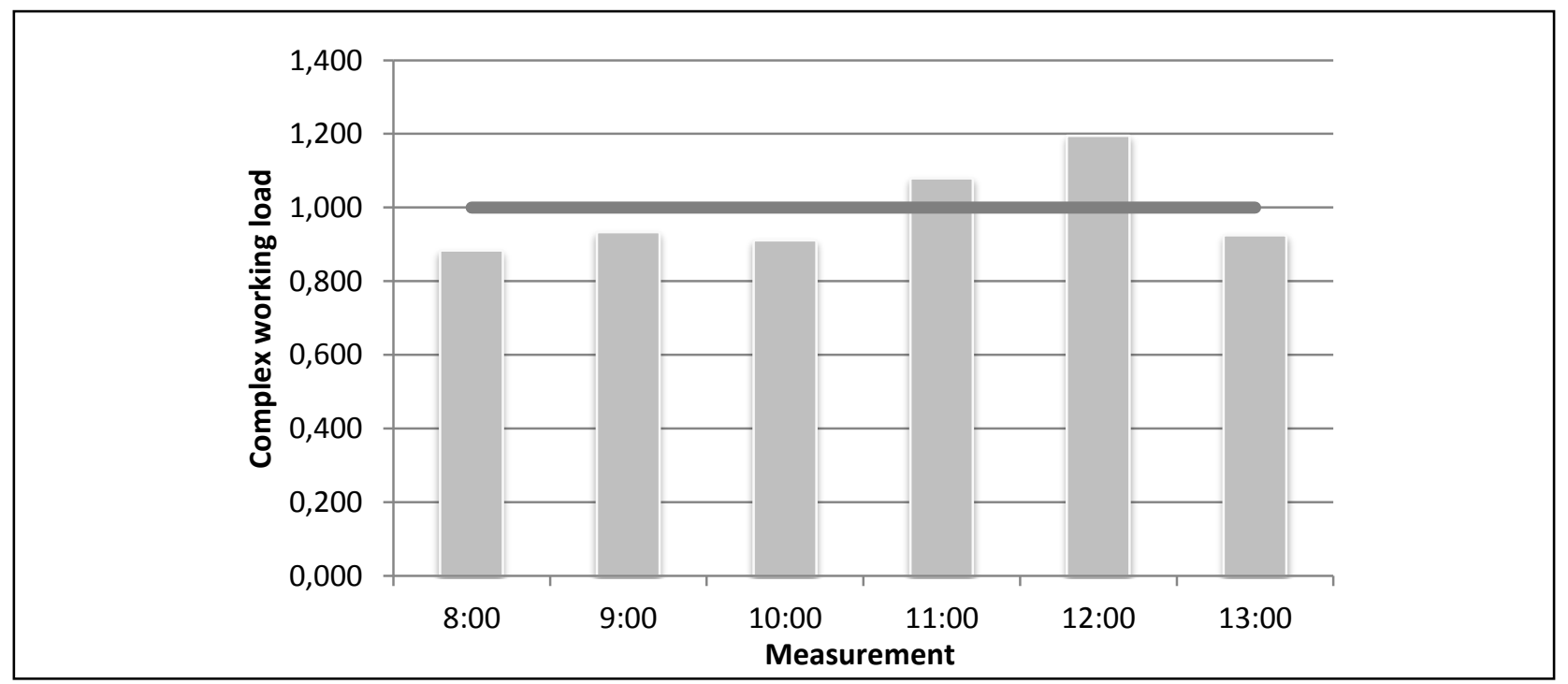

Fig. 2. The complex working load

\section{Conclusion}

Today we put great importance on all factors that affect the quality and safety working environment, but many of them are not in accordance with prescribed standards. Microclimatic parameters (conditions) have much greater impact on 
subjective well-being human, the quality of rest and real labour productivity than other specific pollutants, for example noise. Knowing the climate conditions of the environment, in which research on the working conditions in terms of the effect of temperature, humidity and airflow is being performed, is an important step towards optimizing the internal components to reduce the impact of these factors.

In order to prevent the effects arising from thermal stress due to failure of the thermoregulation mechanisms, microclimatic indices of stress have been devised in order to point out the existence of thermal stress risk as a result of metabolic situations or excessive physical strain.

To evaluate the comfort of working environment is very important, because only employee working in optimal conditions can provide the activity that leads to the growth of society and a stable market position. It is important to ensure the quality of the real situation because it can provide reliable, relevant and timely information that will be used when deciding on preventive or corrective measures.

As a result of the general improvement of microclimatic conditions in the working environment and the adoption, in many jobs, from air conditioning systems, further research will be focused on the determination of more complex indexes of evaluation, with aim to include the existence of the subjective conditions for thermal comfort.

\section{Acknowledgements}

This contribution was worked - out frame within the frame project No 032TUKE$4 / 2012$ „ICT aided new forms of learning and increasing the efficiency of education for environmental study programs“.

\section{References}

Hanker, J. et al. (1978). Ergonomy in industry. Alfa, MDT 331.015.11, Bratislava Hnilica, R. (2011). Development of framework for assessment of combined effects of risk factors, Available from:http://www.tuzvo.sk/files/FEVT/fakulta_fevt/hnilica-z-akta-fevt-2-20114.pdf Accessed: 2012-07-10

Kapustova, M. (2004). Application of mathematical methods by ecologisation of working environment in engineering operations (in Slovak), Available from: http://www.mtf.stuba.sk/docs//internetovy_casopis/2004/2/kapustova.pdf Accessed: 2012-07-10

Kubani, V. (1998). Psychology of work, PU Presov, ISBN 80-88722-36-8, Presov, Slovak Directive No 544/2007 on the details of health protection against heat and cold stress at Work

Franko, S , Babusova, E. , Badida, M. (2011) Thermography and Possibilities of its Application in Practice. In: Annals of DAAAM for 2011 \& Proceedings of the 22nd International DAAAM Symposium, Vienna, Austria, DAAAM International, 2011 P. 1233-1234. - ISBN 978-3-901509-83-4, ISSN 17269679 